931 FACTAPS RELATED TO THE OCCURRENCE OF RETROLENTAI FIBROPLASIA (FLF). Tania R. Gunn, Jane Easdown, Jacob V. Aranda. McGili University-Montreal.Ch1ldren's Hosp Depts. of Newborn Medicine and Pediatrics, Montreal, CANADA. RLF relates inversely to maturity and directly to duration of $\mathrm{O}_{2}$ therapy. Other factors which may influence the occurrence of RLF were studied in all 84 infants $<1500 \mathrm{~g}$ birth weight in 1975 and 1976. 77 children had indirect ophthalmoscopy, wh1le 7 had refused examination or had been lost to follow-up. Infants with cicatricial RLF were compared to those without.

\section{\# of infants}

\section{\# of infants}

Birth weight $(\mathrm{g})$

Gestational age (wks)

Apnea

Apnea \& Bagging

Septicemia

Myopia

$$
\frac{\text { NO RLF }}{50}
$$

$1157 \pm 257$

$30.4 \pm 2.4$

38

24

3

Dener factors shown to lncrease ( $p<0.05)$ RLF occurrence were: durations of CDAP, NPO and parenteral nutrition, as well as epi sodes of capillary $\mathrm{PO}_{2}>40 \mathrm{mmHg}$, maximum weight loss, days to regain birth weight and blood transfused/kg. Analysis of infants who required bag and mask resuscitation for apnea revealed significant increase of RLF only with the factors listed in the table. High myopia requiring corrective lenses increased with cicatric1al RLF. Data suggest that apnea and bagging, septicemia and severity of illness are important determinants in occurrence of

\section{MIXED AND OBSTRUCTIVE SLEEP APNEA IN 3-MONTH-OLD} CONTRLL AND NEAR MISS FOR SUDDEN INFANT DEATH SYNDROM Lynn E. Nage1 (Spon. by J. Johnson) (NICHD \# HD 08339) Stanford Univ. Med. Center, Dept. of Ped, and Sleep Clinic, Stanford, CA.

Fifteen full term near miss for SIDS (NM) infants and ten normal controls (C) at 3 months of age were polygraphically recorded for $24 \mathrm{hrs}$. The near miss episode, in which the infant during sleep was found apne1c and cyanotic, was reported by the parents. The variables monitored were EEG, EOG, ECG, and EMG. Respiration was studied with abdominal and thoracic strain gauges and nasal thermistors to assess presence of air flow. Apneic episodes were subdivided by type (central, obstructive [0] and mixed [M]) and duration ( $3-6 \mathrm{sec}, 6-10 \mathrm{sec},>10 \mathrm{sec})$ and relation to sleep state (REM and NREM). The recording was also subdivided into 3 time periods: morning (0600-1200), aftemoon (1200-1600) and night (2000-0600) and a similar analysis was performed as for the 24-hr recording. Results: The only significant variable differentiating $N M$ from $C$ infants was $M \& O$ events. Data is expressed as a sleep apnea hourly index.

\begin{tabular}{|c|c|c|c|c|}
\hline & NREM & REM & t. Sleep & \\
\hline$\underset{\mathrm{NM}}{\mathrm{C}}$ & $\begin{array}{r}.16 \pm .19 \\
81 \pm .95\end{array}$ & $76 \pm .77$ & & \\
\hline U & $.06 \pm .07$ & 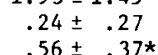 & $\begin{array}{r}.13 \pm \\
39+\end{array}$ & \\
\hline
\end{tabular}

$\mathrm{NM}$ and $\mathrm{C}$ infants were differentiated by $M \& O$ sleep apnea during $24-\mathrm{hr}$ and night monitoring but not during day time naps,

933 EVALUATION BY NON-MEDICAL PERSONNEL OF COMMUNITY HOSPITAL NEONATAL CPR William R. Arney, Jill N Nagy, Joyce Peabody (Spon. by Saul Blatman) (Dartmouth Medical School, Hanover, N. H. and Univ. of Vermont Col. of Medicine, Burlington, Vt.)

The Vt./N.H. Regional Perinatal Program conducted and evaluated a series of infant CPR courses given for M.Ds and RNs in eleven hospitals. Each intervention hospital was matched with a control hospital for size, staffing, distance from center, and an objective test of nursing knowledge. A drill and protocol were designed so that performance could be evaluated by nonmedical personnel. Pre- and post-drills two weeks apart resulted in complete data from 6 control/intervention pairs. Most common erpors included: (1) improper positioning, (2) suctioning with $>20 \mathrm{mmHg}$ pressure, (3) no cardiac massage, or when done, (4) lack of support and (5) confusion about rate, (6) failure to intubate or (7) failure to stabilize tube and 8) no ventilation between intubation attempts.

our data indicate that just giving a drill caused an improvement in skills. Both intervention and control hospitals were more likely to do cardiac massage in the post-test. Intervention hospitals increased intubation efforts but with errors. We conclude that: (a) just testing improves skills, (b) CPR courses raise knowledge levels but (c) people need multiple contacts to refine skills and (d) non-medical personnel can effectively evaluate neonatal CPR via a clinical drill.
934

HUMAN MILK: COMPARISON OF NITROGEN (N) COMPOSITION IN MILK FROM MOTHERS GIVING BIRTH PREMATURELY OR AT
TERM. Stephanie A. Atk1nson, G. Harvey Anderson, $M$. Heather Bryan, University of Toronto and The Hospital for Sick Children, Departments of Nutrition and Food Sclence, and Pedlatrics, Toronto.

Complete 24-hour expressions of human breast milk were collected serially from 7 mothers giving birth at 26-33 wh gestation (Premature, PT) and 8 mothers at $38-40$ wk gestation (Fullterm,FT) during the first 29 days postpartum. Individual milk samples (69) were analyzed for total $\mathrm{N}$ concentration. The regression lines describing the change in $N$ concentration $(y)$ with time in days (d) were $y=368-4.36 d(r=-0.60, p<0.01)$, and $y=$ $310-4.15 \mathrm{~d}(\mathrm{r}=-0.80, \mathrm{p}<0.01)$, for PT and FT, respectively. Total $\mathrm{N}$ concentration in PT milk was significantly higher $(p<0.01)$ than in FT milk over the time studied. The distribution of total $\mathrm{N}$ in non-protein N (NPN) and protein $N$ was determined on 7 PT and 8 FT pooled milk samples, representing specific day intervals within each group. NPN as a percent of total $\mathrm{N}$ remained constant over the f1rst 29 days of lactation and was similar in the two groups ( $F T=18.9 \pm 0.7, P T=17.8+0.8$, mean + SEM). The proportions of $N$ derived from free amino acld $N$ (FAAN) and urea N(UN) were constant with time and as a percentage of NPN were similar in the FT $(7.9+0.4$ FAAN; $26.8+1$. 7UN $)$ and PT $(8.4+0.7$ FAAN; $25.8 \pm 2.0 \mathrm{UN})$ groups. It is concluded that the higher $\overrightarrow{\mathrm{N}}$ concentration of PT milk is due to proportional increments in both the protein and NPN fractions.

\section{5} asagar ALSM, Uni $;$. Gupta, E. John, and D. Vidyolazol Ane, and adrenergic antagonits) is known to increase $\mathrm{PaO2}$ in newborns with severe hypoxia due to a variety of causes. We used Prisc. in 33 infants wlth severe respiratory distress when $\mathrm{PaO} 2$ was $<50 \mathrm{mmHg}$ in $\mathrm{FlO2}>0.8$ and ventilatory peak pressure $>35 \mathrm{~cm}$. $\mathrm{H}_{2} \mathrm{O}$. $11 / 33$ developed ARF. Pertinent data of infants developing ARF (Gr. 1) and those without (Gr. II) is shown in the table. There were no differences in birth weight is shown in the table. There were no differences in birth weight \& gest-

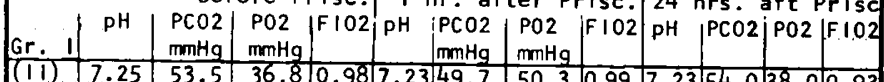

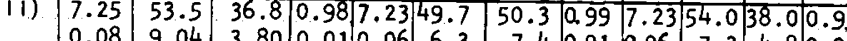

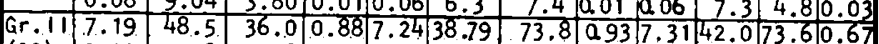

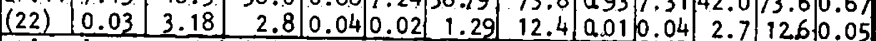

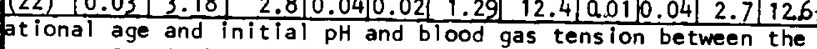
groups. Gr. I showed hypotension (42.411.5 to $38.0 \pm 1.6 \mathrm{mmHg})$, drop in urine output $(2.4 \pm 0.8$ to $0.14 \pm .04 \mathrm{mi} / \mathrm{kg} / \mathrm{hr}$.) 24 hours following therapy. They also falled to show improvement in Pa02. Gr. 11 had significantly higher BP $(51.7+2.3 \mathrm{mmHg})$ than Gr. $1,(\mathrm{p}<.01)$. A significant rise $(p<.01)$ in $\mathrm{PO2}$ following Prisc. was also seen in this group. Urine output before and after Prisc. therapy was

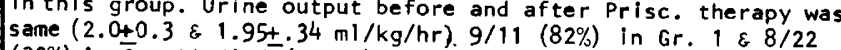
$(32 \%)$ in $\bar{G} r$. 11 died $(p<.01)$. The data suggests that priscoline therapy in hypotensive neonates is associated with lack of rise in $\mathrm{PC2}$, ARF and increased mortality. Extreme caution is necessary
before instituting Prisc. therany.

\section{6}

RAPID FLUOROMETRIC DETERMINATION OF BILIRUBIN LEVELS AND THE RESERVE BINDING CAPACITY IN THE BLOOD OF NEOFlores, AngTES. William E. Blumberg, Josef Eisinger, Jorge A. Lamola, Smantha Patel and David M. Zuckerman, Binding tories, Murray Hill, NJ 07974. (Spon. by Audrey Brown) Binding of (unconjugated) bilirubin (BR) to human blood frac-
ions has been studied using spectrofluorometry, and the results obtained were used to interpret the titration curve of $B R$ in Whole blood as determined by front face fluorometry. It is found that BR fluorescence from whole blood reflects only that BR tightly bound to albumin the normal BR transport protein. A signifi cant amount of BR may be bound to erythrocytes as well as to

plasma proteins other than albumin, and is essentially non-fluor scent. Detergents can extract $B R$ from all blood sites. Since $B R$ is fluorescent in detergent micelles, total blood BR can be assayed. A significant difference between albumin-bound BR and total blood $B R$ reflects a saturation of the albumin binding or a reduced albumin binding affinity. The reserve albumin binding capacity for $B R$ can be obtained from the incremental fluorescence measured upon adding a saturating quantity of $B R$ to the specimen. All three parameters (albumin-bound BR, total blood BR, and reserve albumin capacity) can be measured simply and within a few minutes on less than $100 u$ l blood by the use of a dedicated front face fluorometer (hematofluorometer), facitat ing effective management of neonatal jaundice. Prototypes of the BR-hematofluorometer in two intensive care nurseries have yielded results in ex cellent agreement with those obtained by present, more laborious methods, which are impractical for routine use. 